\title{
Relationship Among Atrial Fibrillation, CHADS2 Score and Ischaemic Stroke in Patients With Coronary Artery Disease: A Propensity Score Matching Study
}

\section{Boqun Shi}

Second Hospital of Hebei Medical University

Demin Liu

Second Hospital of Hebei Medical University

Qian Wang

Second Hospital of Hebei Medical University

\section{Xue Geng}

Second Hospital of Hebei Medical University

Qian Hou

Second Hospital of Hebei Medical University

Guoqiang Gu

Second Hospital of Hebei Medical University

\section{Ruiqin Xie}

Second Hospital of Hebei Medical University

Wei Cui ( $\nabla$ cuiweihb2h@163.com )

Second Hospital of Hebei Medical University https://orcid.org/0000-0002-2480-8667

Research article

Keywords: Atrial fibrillation, CHADS2 score, Coronary artery disease, Ischaemic stroke

Posted Date: September 15th, 2020

DOI: https://doi.org/10.21203/rs.3.rs-73095/v1

License: (c) (1) This work is licensed under a Creative Commons Attribution 4.0 International License. Read Full License 


\section{Abstract}

Objective: The purpose of this study was to investigate the relationship among atrial fibrillation (AF), $\mathrm{CHADS}_{2}$ score and ischaemic stroke in patients with coronary artery disease.

Methods: A total of 2335 patients with coronary artery disease were included. They were divided into a nonischaemic stroke group $(n=1997)$ and an ischaemic stroke group $(n=388)$. Propensity score matching (PSM) was used to match ischaemic stroke patients with nonischaemic stroke patients in a 1:4 ratio. The relationship between $\mathrm{AF}, \mathrm{CHADS}_{2}$ score and ischaemic stroke was evaluated using a univariate generalized linear model in different age, body mass index, and coronary artery disease subgroups. Univariate and multivariate generalized linear models were used to evaluate the relationship between AF and ischaemic stroke in different models.

Results: Compared with the nonischaemic stroke group, the rate of $A F(8.81 \%$ vs. $14.20 \%, P=0.002)$ in the ischaemic stroke group was higher. The proportion of patients with ischaemic stroke was significantly different between the AF group and the non-AF group ( $19.04 \%$ vs. $28.74 \%, P=0.003)$. With increasing $\mathrm{CHADS}_{2}$ score, the incidence of AF gradually increased ( $P$ for trend $<0.001$ ). With increasing AF burden, the rate of ischaemic stroke increased continuously ( $P$ for trend $<0.001)$. Subgroup analysis showed that the trend towards increased stroke risk in the AF group was consistent across the various subgroups. Multivariate analysis demonstrated that paroxysmal and nonparoxysmal AF were not associated with ischaemic stroke compared with the absence of AF.

Conclusion: After adjusting for confounding factors, the correlation between AF and ischaemic stroke decreased. Atherosclerotic factors may play an important role in ischaemic stroke in patients with coronary heart disease.

\section{Background}

Atrial fibrillation (AF) is a common arrhythmia in clinical practice [1-3]. Although evidence in recent decades has indicated a strong association between $\mathrm{AF}$ and ischaemic stroke [4,5], a gap remains in our understanding of the mechanism underlying this association. The current view is that AF causes blood to clot and emboli to detach, resulting in cerebral embolism [5]. This mechanism has long been considered the leading cause of ischaemic stroke [6]. However, recent studies have shown that the pathogenesis of ischaemic stroke associated with AF is more complex and involves other factors in addition to arrhythmias [7]. Coronary artery disease and ischaemic stroke have similar risk factors [8], such as hypertension and advanced age. The purpose of this study was to explore the relationship among AF, $\mathrm{CHADS}_{2}$ score and ischaemic stroke in patients with coronary heart disease and to further understand the role of $A F$ in ischaemic stroke in patients with coronary heart disease; the results will have far-reaching significance for future treatment strategies.

\section{Materials And Methods}




\section{Study population}

This study is a cross-sectional study conducted according to the STROBE guidelines. A total of 2,335 patients with coronary artery disease were admitted to the first department of The Cardiovascular Department of the Second Hospital of Hebei Medical University from September 2016 to May 2019.

Patient demographic information, medical history and laboratory assessments were collected and recorded. As shown in Figure 1, 262 patients were excluded for cerebral haemorrhage, subarachnoid haemorrhage, or unknown stroke history. Finally, 2,335 patients were included in this analysis.

The study population was divided into different subgroups according to sex, age, body mass index, type of coronary artery disease, and $\mathrm{CHADS}_{2}$ score $\geq 3$.

Coronary artery disease was defined as significant narrowing $(\geq 50 \%)$ of the coronary lumen detected either invasively or noninvasively and further defined as one or more of the following types: stable coronary artery disease (SCAD), unstable angina (UA), non-ST-elevation myocardial infarction (NSTEMI), ST-elevation myocardial infarction (STEMI), previous myocardial infarction (previous $\mathrm{MI}$ ), and ischaemic cardiomyopathy. Specific diagnoses were performed on the basis of standard reference guidelines.

In this study, ischaemic stroke included either a previous history of ischaemic stroke or new onset of ischaemic stroke during hospitalization.

AF was classified into paroxysmal, persistent, long-standing persistent and permanent AF, which were determined according to the 2014 American College of Cardiology (ACC)/American Heart Association (AHA)/Heart Rhythm Society (HRS) task force on practice guidelines and the 2016 European Society of Cardiology (ESC) guidelines $[9,10]$. In this study, persistent, long-standing persistent, and permanent AF were grouped and collectively referred to as nonparoxysmal AF.

The $\mathrm{CHADS}_{2}$ score is a clinically commonly used prediction model to identify the risk of ischaemic stroke in patients with nonvalvular $A F$, which was calculated by assigning 2 points for ischaemic stroke or transient ischaemic attack and 1 point for each other component, including heart failure, hypertension, age $\geq 75$ years and diabetes. The $\mathrm{CHADS}_{2}$ score was calculated for each patient at discharge.

We defined diabetes mellitus (DM) as a casual plasma glucose concentration $\geq 200 \mathrm{mg} / \mathrm{dL}$, fasting plasma glucose concentration $\geq 126 \mathrm{mg} / \mathrm{dL}$, 2-hour plasma glucose concentration $\geq 200 \mathrm{mg} / \mathrm{dL}$ from a $75 \mathrm{~g}$ oral glucose tolerance test, or receiving drugs or insulin for DM. Hypertension was defined as systolic blood pressure $\geq 140 \mathrm{mmHg}$, diastolic blood pressure $\geq 90 \mathrm{mmHg}$ or taking antihypertensive medication. Dyslipidaemia was defined as low-density lipoprotein cholesterol (LDL-C) $\geq 140 \mathrm{mg} / \mathrm{dL}$, highdensity lipoprotein cholesterol (HDL-C) $<40 \mathrm{mg} / \mathrm{dL}$, or triglycerides $150 \mathrm{mg} / \mathrm{dL}$. Heart failure included past or current signs and symptoms of heart failure with both low $(<40 \%)$ and preserved ejection fraction (EF) $(\geq 40 \%)$ and/or other clinical evidence of cardiac dysfunction. Chronic kidney disease (CKD) referred to 
an estimated glomerular filtration rate $<60 \mathrm{~mL} / \mathrm{min}$ per $1.73 \mathrm{~m}^{2}$. Left atrial diameter (LA) and EF were measured by transthoracic echocardiography or transoesophageal echocardiography.

\section{Statistical analysis}

The investigators performed the data analysis using Empower (R) (www.empowerstats.com, X\&Y solutions, Inc. Boston MA) and R 3.6.3 (http://www.R-project.org). Continuous variables in this study did not conform to a normal distribution, which were described as the median and interquartile range (IQR) and compared using the Mann-Whitney test. Categorical variables were expressed as counts and composition ratios and were compared using the chi-square test or Fisher exact test as appropriate.

Given the inherent differences between patients with or without ischaemic stroke, we calculated a propensity score for the following variables: sex, age, and body mass index. The propensity score was estimated by using a logistic regression model. The matching process was based on the nearest neighbour matching method without replacement, under a 0.01 calliper to perform 1:4 matching, which yielded subjects with stroke and matched subjects without stroke. A standardized difference of less than 0.1 indicated an excellent balance after PSM.

To control for potential covariates, we used multivariate generalized linear regression models. We constructed two models for the association of AF with ischaemic stroke. This multivariate analysis, adjusting for any possible confounding variables of statistical significance in the univariate analysis $(\mathrm{P}<$ 0.1 ), was performed to identify independent risk predictors. We also adjusted for features that, when added to this model, changed the matched odds ratio by at least $10 \%$. The Cochran-Mantel-Haenszel test was used in the analysis to calculate $P$ for trend. The likelihood ratio test followed the tests for impact adjustment for subgroup markers. A two-tailed $P$ value $<0.05$ was considered statistically significant in this study. The missing values were not deleted or filled, and the empty values were directly retained for data analysis.

\section{Results}

\section{Patient characteristics}

A total of 2335 patients with coronary artery disease were enrolled in this study, including 1,997 patients without ischaemic stroke (85.52\%) and 338 patients with ischaemic stroke (14.48\%). The matched crosssectional analysis included 1,685 patients (1,348 patients without ischaemic stroke and 337 patients with it). The patients' baseline characteristics before and after matching are shown in Table 1.

Before PSM, compared with the nonischaemic stroke group, the ischaemic stroke group was older (63.00 vs $65.00, P<0.001)$, and its proportions of SCAD (6.41\% vs $10.65 \%, P=0.005)$, STEMI ( $3.96 \%$ vs $6.80 \%$, $\mathrm{P}=0.018)$, and previous $\mathrm{MI}(10.27 \%$ vs $14.50 \%, \mathrm{P}=0.021)$ were higher. The proportion of UA $(73.66 \%$ vs $67.75 \%, P=0.024)$ was lower, and the proportions of heart failure (15.62\% vs $21.30 \%, P=0.009)$, hypertension (65.45\% vs $77.51 \%, \mathrm{P}<0.001)$, AF ( $8.81 \%$ vs $14.20 \%, \mathrm{P}=0.002)$, CKD (1.95\% vs $3.85 \%$, 
$\mathrm{P}=0.043)$, and aortic atherosclerosis $(26.81 \%$ vs $84 \%, \mathrm{P}<0.001)$ were higher. The creatinine levels $(69.00$ vs $72.00, P=0.001)$, pulse wave velocity (PWV) $(1556.50$ vs $1623.00, P<0.001)$ and CHADS $_{2}$ scores $(1.00$ vs $3.00, P<0.001)$ were also higher. These differences were statistically significant.

After PSM, compared with the nonischaemic stroke group, the proportions of STEMI (3.78\% vs $6.53 \%$, $\mathrm{P}=0.027), \mathrm{UA}(73.37 \%$ vs $67.95 \%, \mathrm{P}=0.047)$, hypertension ( $66.69 \%$ vs $77.74 \%, P<0.001), \operatorname{AF}(8.83 \%$ vs $14.24 \%, P=0.003)$, and aortic atherosclerosis $(28.94 \%$ vs $43.98 \%, P<0.001)$ were higher in the ischaemic stroke group. The serum creatinine level ( 70.00 vs $72.00, P=0.018)$ and $\mathrm{CHADS}_{2}$ score (1.00 vs 3.00 , $P<0.001)$ were also higher. These differences were statistically significant.

A comparison of the baseline data of patients with and without AF after PSM is shown in Table 2. Compared with the non-AF group, the AF group was older (63.50 vs $69.00, P<0.001$ ); had higher rates of $\operatorname{SCAD}(4.61 \%$ vs $31.14 \%, \mathrm{P}<0.001)$, previous $\mathrm{MI}(10.94 \%$ vs $17.37 \%, \mathrm{P}=0.014)$, ischaemic cardiomyopathy ( $1.58 \%$ vs $5.99 \%, P<0.001)$, and UA $(74.57 \%$ vs $51.50 \%$; had lower rates of STEMI $(4.68 \%$ vs $1.20 \%$, $P=0.036)$, heart failure $(13.90 \%$ vs $53.29 \%, P<0.001)$, valvular heart disease $(1.91 \%$ vs $6.59 \%, P<0.001)$, CKD (1.84\% vs $4.79 \%, P=0.012)$, smoking ( $19.50 \%$ vs $12.57 \%, P=0.03)$, and aortic atherosclerosis (30.53\% vs $44.58 \%)$; and had higher serum creatinine level ( 69.00 vs $79, P<0.001)$, LA (34.00 vs $38.00, P<0.001)$, PWV (1565.00 vs 1734.75, $\mathrm{P}<0.001)$, and $\mathrm{CHADS}_{2}$ score (1.00 vs 2.00, $\left.\mathrm{P}<0.001\right)$. Furthermore, $\mathrm{ABI}(1.08$ vs $1.06, P=0.004)$ and $E F(61.74 \%$ vs $60.78 \%, P<0.001)$ were lower. These differences were statistically significant. The proportion of patients with ischaemic stroke was significantly different between the two groups $(19.04 \%$ vs $28.74 \%, P=0.003)$.

\section{Subgroup analysis}

A subgroup analysis defined by baseline characteristics between the AF group and the non-AF group was performed (Figure 3). A trend towards increased risk of stroke in the AF group was observed among the following subgroups: male, age $\geq 65$ years, BMI $\geq 24 \mathrm{~kg} / \mathrm{m}^{2}$, non-UA, non-NSTEMI, non-STEMI, nonprevious $\mathrm{MI}$ and nonischaemic cardiomyopathy. Interestingly, AF seemed to be a protective factor in the $\mathrm{CHADS}_{2} \geq 3$ subgroup. Meanwhile, the subgroup analysis did not indicate any significant interactions between ischaemic stroke and these stratification variables.

\section{Association between atrial fibrillation and ischaemic stroke in multivariate analysis}

The univariate analysis of the relationship between AF and ischaemic stroke after PSM showed that paroxysmal AF was not associated with ischaemic stroke, while nonparoxysmal AF was associated with ischaemic stroke $(\mathrm{OR}=1.90,95 \% \mathrm{Cl}: 1.16-3.10, \mathrm{P}=0.0104)$. Multivariate analysis showed that in model I and model II, neither paroxysmal nor nonparoxysmal AF was associated with ischaemic stroke compared with no AF (Table 3). Model I was adjusted for stable angina, aortic atherosclerosis, LA, PWV, and $\mathrm{CHADS}_{2}$ score. Model II was adjusted for STEMI, previous MI, ischaemic cardiomyopathy, CKD, and factors in model I. 
With increasing $\mathrm{CHADS}_{2}$ score, the incidence of AF gradually increased ( $P$ for trend $<0.001$, Figure $3(\mathrm{a})$ ). A similar association was observed with increasing $A F$ burden: the rate of ischaemic stroke increased continuously (P for trend $<0.001$, Figure $3(b)$ ).

\section{Discussion}

\section{Atrial fibrillation and ischaemic stroke have common risk factors}

The results of this study suggest that age, heart failure, hypertension, CKD, creatinine level, aortic atherosclerosis, PWV, and $\mathrm{CHADS}_{2}$ scores are associated with ischaemic stroke and AF.

Previous studies have shown that age, male sex, hypertension, DM, valvular heart disease, heart failure, coronary artery disease, CKD, inflammatory disease, obstructive sleep apnoea syndrome and smoking are common risk factors for $A F$ and ischaemic stroke $[9,11,12]$. Potential risk factors, such as obesity and metabolic syndrome, contribute to the development of AF and atrial cardiomyopathy through a variety of mechanisms [13]. The Framingham Heart Study [14] pointed out that the lifetime risk of AF was approximately $20 \%$ with an optimal risk profile, lower than that with a high-risk profile (38.4\%). The UK Biobank study [13] confirmed that there were significant differences in AF risk between the ideal lifestyle group, the general lifestyle group, and the weak lifestyle group, regardless of genetic risk. As more common risk factors were considered, the association between $\mathrm{AF}$ and ischaemic stroke was reduced, suggesting a confounding pattern.

\section{Possible mechanism of ischaemic stroke in patients with coronary artery disease complicated with AF}

In patients with coronary heart disease, the univariate analysis showed that AF was associated with ischaemic stroke, while the association between AF and ischaemic stroke decreased or even disappeared after the multivariate analysis, which adjusted for other risk factors. In the subgroup analysis, AF appeared to be a protective factor in the $\mathrm{CHADS}_{2} \geq 3$ subgroup. It is speculated that the risk of ischaemic stroke does not increase after the $\mathrm{CHADS}_{2}$ score reaches a certain threshold in patients with coronary artery disease. These findings suggest that atherosclerotic factors may play an important role in ischaemic stroke in patients with coronary heart disease.

\section{Relationship between atrial fibrillation burden and ischaemic stroke}

In this study, the univariate analysis showed that paroxysmal AF was not associated with ischaemic stroke, while nonparoxysmal AF was associated with ischaemic stroke. The trend test showed that with increasing AF burden, the rate of ischaemic stroke increases continuously. These findings suggest that compared with patients with paroxysmal AF, patients with nonparoxysmal AF have a higher risk of ischaemic stroke; that is, AF burden is positively correlated with ischaemic stroke.

Although many studies have found a dose-response relationship between AF load and ischaemic stroke [15-17], not all the results are consistent. The recent KP-Rhythm study identified a higher risk of stroke in 
the high-load group ( $>11 \%$, approximately $2.5 \mathrm{~h} / 24 \mathrm{~h}$ ) [17]. There is no uniform standard for AF burden thresholds that significantly increase the risk of thrombosis ${ }^{[52,53]}$. The current guidelines $[9,10]$ generally consider that if the duration of $\mathrm{AF}$ is less than 48 hours, there is no need to perform transoesophageal echocardiography. Regardless of the $\mathrm{CHA}_{2} \mathrm{DS}_{2}$-VASc score and the method used to restore the sinus rhythm, cardioversion can be performed without anticoagulation. However, whether the 48-hour threshold applies to all patients with AF is debatable[18]. In addition, a brief episode of subclinical AF doubles the risk of ischaemic stroke in elderly patients [19]. However, there was no significant increase in the risk of ischaemic stroke in young, healthy patients with AF [20]. Additionally, the atrial remodelling seen in animal models of AF occurred at least a week after continuous rapid pacing [21]. Therefore, any atrial changes caused by AF are unlikely to explain the association between a short (6-minute) AF episode and an increased risk of ischaemic stroke [19]. Overall, these conflicting data are insufficient to establish a clear dose-response relationship between AF burden and the risk of ischaemic stroke.

In addition, if AF, an arrhythmia, is the primary cause of thromboembolism, then rhythm control to reduce the AF load should significantly reduce or eliminate the risk of ischaemic stroke. However, in a metaanalysis of eight randomized clinical trials, rhythm control did not affect the risk of ischaemic stroke [22]. The CABANA study, involving 2,204 patients in 126 centres in 10 countries, suggested that catheter ablation of $A F$, although more effective for rhythm control than drug therapy, also did not reduce the incidence of ischaemic stroke [23]. At present, no large-scale clinical study has demonstrated that maintaining sinus rhythm in patients with AF can prevent ischaemic stroke, and there is no substantial evidence to support the safety of discontinuation of anticoagulant drugs after AF ablation. There is no reliable evidence that $\mathrm{AF}$ is a necessary condition for atrial thrombus formation.

\section{Antithrombotic therapy in coronary artery disease patients with atrial fibrillation}

Beyond one year after coronary stenting, current guidelines $[9,24-26]$ have consistently recommended lifelong oral anticoagulant medication without antiplatelet therapy in patients with AF. However, the evidence for discontinuation of antiplatelet therapy in the above guidelines is insufficient, and the above decision was made based on a small number of observational studies [27]. The 2018 ESC guidelines for myocardial revascularization [28] suggested that aspirin should be taken lifelong for secondary prevention of SCAD after $\mathrm{PCl}$, and even the duration of dual antiplatelet therapy should be extended for acute coronary syndrome (ACS). In patients with AF and SCAD beyond one year after PCI or ACS, the optimal antithrombotic regimen remains uncertain. According to this study of patients with coronary artery disease, there are many risk factors for systemic atherosclerosis, which can cause ischaemic stroke through atrial and nonatrial mechanisms. These patients may require a dual antithrombotic combination of oral anticoagulation and single antiplatelet therapy to avoid systemic embolism and stroke. The OAC-ALONE trial failed to establish the noninferiority of oral anticoagulation alone compared with a regimen of oral anticoagulation and single antiplatelet therapy because patient enrolment was prematurely terminated, leading to an underpowered sample size [29]. The AFIRE study demonstrated that rivaroxaban monotherapy was noninferior to combination anticoagulant therapy for efficacy and superior for major bleeding events in patients with AF and stable coronary artery disease [30]. However, 
the available evidence falls short of level 1 and class A status, and whether the current recommendation of anticoagulation alone beyond one year after coronary stenting is an optimal strategy remains to be further studied [31, 32].

\section{Study strength and limitations}

The innovation of this study is that the object of this study is specifically patients with coronary artery disease, who tend to have a higher degree of atherosclerosis than patients with AF alone, and atherosclerotic factors may play a more significant role in the mechanism of ischaemic stroke.

The limitations of this study are that it was a retrospective cross-sectional study, and ischaemic stroke, $\mathrm{CHADS}_{2}$ score, and AF were measured at the same time. Complex aortic plaques and peripheral artery disease were not examined in these patients, so we cannot calculate the $\mathrm{CHA}_{2} \mathrm{DS}_{2}-\mathrm{VASc}$ score and explore its relationship with ischaemic stroke, which still needs further research.

\section{Conclusion}

After adjusting for confounding factors, the correlation between AF and ischaemic stroke abated. Thus, the idea that prompted the current thinking that AF leads to cerebral embolism is incomplete. A direct link between ischaemic stroke and AF is not consistent with Hill's principle of timeliness, specificity, and concentration-response relationship. In contrast, induction of AF by abnormal and systemic atherosclerosis risk factors and an abnormal atrial substrate model conforms to the existing evidence of ischaemic stroke. Thus, emphasizing systemic treatment for vascular risk factors can reduce the incidence of AF along with that of ischaemic stroke and reduce the burden of this disabling disease.

\section{Abbreviations}

BMI: body mass index; CAD: coronary artery disease; SCAD: stable coronary artery disease; UA: unstable angina; NSTEMI: non-ST-elevation myocardial infarction; STEMI: ST-elevation myocardial infarction; previous MI: previous myocardial infarction; AF: atrial fibrillation; DM: diabetes mellitus; COPD: chronic obstructive pulmonary disease; CKD: chronic kidney disease; LDL-C: low-density lipoprotein cholesterol; LA: left atrial diameter; EF: ejection fraction; PWV: pulse wave velocity; ABI: ankle-brachial index

\section{Declarations}

\section{Acknowledgements}

Not applicable.

\section{Authors' contributions}

Study conception and design was performed by BQS, DML, and WC. Data collection was performed by BQS, DML, QW, XG, QH, GQG and XRQ. Statistical analysis and the interpretation of the data were 
performed by BQS. BQS wrote the first draft of the paper; DML and WC revised the article. This manuscript was read and approved by all credited authors.

\section{Funding}

None.

\section{Availability of data and materials}

The datasets used and/or analysed during the current study are available from the corresponding author on reasonable request.

\section{Ethics approval and consent to participate}

The study was conducted in line with the principles of the Helsinki Declaration. Ethical approval was given by the Research Ethics Committee of the Second Hospital of Hebei University. The present study retrospectively analysed anonymized data, thus no informed consent was required.

\section{Consent for publication}

Not applicable.

\section{Competing interests}

The authors declare that they have no competing interests.

\section{References}

1. Rahman F, Kwan GF, Benjamin EJ: Global epidemiology of atrial fibrillation. Nat Rev Cardiol 2014, 11(11):639-654.

2. Zimetbaum P: Atrial Fibrillation. Ann Intern Med 2017, 166(5):ITC33-ITC48.

3. Bai Y, Wang YL, Shantsila A, Lip GYH: The Global Burden of Atrial Fibrillation and Stroke: A Systematic Review of the Clinical Epidemiology of Atrial Fibrillation in Asia. Chest 2017, 152(4):810820.

4. Wolf PA, Abbott RD, Kannel WB: Atrial fibrillation as an independent risk factor for stroke: the Framingham Study. Stroke 1991, 22(8):983-988.

5. Wolf PA, Dawber TR, Thomas HE, Jr., Kannel WB: Epidemiologic assessment of chronic atrial fibrillation and risk of stroke: the Framingham study. Neurology 1978, 28(10):973-977.

6. Caplan LR: Atrial Fibrillation, Past and Future: From a Stroke Non-Entity to an Over-Targeted Cause. Cerebrovasc Dis 2018, 45(3-4):149-153.

7. Kamel H, Okin PM, Elkind MS, ladecola C: Atrial Fibrillation and Mechanisms of Stroke: Time for a New Model. Stroke 2016, 47(3):895-900. 
8. Soler EP, Ruiz VC: Epidemiology and risk factors of cerebral ischemia and ischemic heart diseases: similarities and differences. Curr Cardiol Rev 2010, 6(3):138-149.

9. Kirchhof P, Benussi S, Kotecha D, AhIsson A, Atar D, Casadei B, Castella M, Diener HC, Heidbuchel H, Hendriks J et al: 2016 ESC Guidelines for the management of atrial fibrillation developed in collaboration with EACTS. Eur Heart J 2016, 37(38):2893-2962.

10. January CT, Wann LS, Alpert JS, Calkins H, Cigarroa JE, Cleveland JC, Jr., Conti JB, Ellinor PT, Ezekowitz MD, Field ME et al: 2014 AHA/ACC/HRS guideline for the management of patients with atrial fibrillation: a report of the American College of Cardiology/American Heart Association Task Force on practice guidelines and the Heart Rhythm Society. Circulation 2014, 130(23):e199-267.

11. Hankey GJ: Stroke. Lancet 2017, 389(10069):641-654.

12. Homan EA, Reyes MV, Hickey KT, Morrow JP: Clinical Overview of Obesity and Diabetes Mellitus as Risk Factors for Atrial Fibrillation and Sudden Cardiac Death. Front Physiol 2018, 9:1847.

13. Said MA, Verweij N, van der Harst P: Associations of Combined Genetic and Lifestyle Risks With Incident Cardiovascular Disease and Diabetes in the UK Biobank Study. JAMA Cardiol 2018, 3(8):693-702.

14. Staerk L, Wang B, Preis SR, Larson MG, Lubitz SA, Ellinor PT, McManus DD, Ko D, Weng LC, Lunetta $\mathrm{KL}$ et al: Lifetime risk of atrial fibrillation according to optimal, borderline, or elevated levels of risk factors: cohort study based on longitudinal data from the Framingham Heart Study. BMJ 2018, $361: \mathrm{k} 1453$.

15. Vanassche T, Lauw MN, Eikelboom JW, Healey JS, Hart RG, Alings M, Avezum A, Diaz R, Hohnloser $\mathrm{SH}$, Lewis BS et al: Risk of ischaemic stroke according to pattern of atrial fibrillation: analysis of 6563 aspirin-treated patients in ACTIVE-A and AVERROES. Eur Heart J 2015, 36(5):281-287a.

16. Nuotio I, Hartikainen JE, Gronberg T, Biancari F, Airaksinen KE: Time to cardioversion for acute atrial fibrillation and thromboembolic complications. JAMA 2014, 312(6):647-649.

17. Go AS, Reynolds K, Yang J, Gupta N, Lenane J, Sung SH, Harrison TN, Liu TI, Solomon MD: Association of Burden of Atrial Fibrillation With Risk of Ischemic Stroke in Adults With Paroxysmal Atrial Fibrillation: The KP-RHYTHM Study. JAMA Cardiol 2018, 3(7):601-608.

18. Rankin AJ, Rankin SH: Cardioverting acute atrial fibrillation and the risk of thromboembolism: not all patients are created equal. Clin Med (Lond) 2017, 17(5):419-423.

19. Healey JS, Connolly SJ, Gold MR, Israel CW, Van Gelder IC, Capucci A, Lau CP, Fain E, Yang S, Bailleul C et al: Subclinical atrial fibrillation and the risk of stroke. N Engl J Med 2012, 366(2):120-129.

20. Chao TF, Liu CJ, Chen SJ, Wang KL, Lin YJ, Chang SL, Lo LW, Hu YF, Tuan TC, Wu TJ et al: Atrial fibrillation and the risk of ischemic stroke: does it still matter in patients with a CHA2DS2-VASc score of 0 or 1 ? Stroke 2012, 43(10):2551-2555.

21. De Jong AM, Maass AH, Oberdorf-Maass SU, Van Veldhuisen DJ, Van Gilst WH, Van Gelder IC: Mechanisms of atrial structural changes caused by stretch occurring before and during early atrial fibrillation. Cardiovasc Res 2011, 89(4):754-765. 
22. Al-Khatib SM, Allen LaPointe NM, Chatterjee R, Crowley MJ, Dupre ME, Kong DF, Lopes RD, Povsic TJ, Raju SS, Shah B et al: Rate- and rhythm-control therapies in patients with atrial fibrillation: a systematic review. Ann Intern Med 2014, 160(11):760-773.

23. Packer DL, Mark DB, Robb RA, Monahan KH, Bahnson TD, Poole JE, Noseworthy PA, Rosenberg YD, Jeffries N, Mitchell LB et al: Effect of Catheter Ablation vs Antiarrhythmic Drug Therapy on Mortality, Stroke, Bleeding, and Cardiac Arrest Among Patients With Atrial Fibrillation: The CABANA Randomized Clinical Trial. JAMA 2019, 321(13):1261-1274.

24. Valgimigli M, Bueno H, Byrne RA, Collet JP, Costa F, Jeppsson A, Juni P, Kastrati A, Kolh P, Mauri L et al: 2017 ESC focused update on dual antiplatelet therapy in coronary artery disease developed in collaboration with EACTS: The Task Force for dual antiplatelet therapy in coronary artery disease of the European Society of Cardiology (ESC) and of the European Association for Cardio-Thoracic Surgery (EACTS). Eur Heart J 2018, 39(3):213-260.

25. Lip GYH, Collet JP, Haude M, Huber K: Management of antithrombotic therapy in AF patients presenting with ACS and/or undergoing PCl: A Summary of the Joint Consensus Document of the European Heart Rhythm Association (EHRA), European Society of Cardiology Working Group on Thrombosis, European Association of Percutaneous Cardiovascular Interventions (EAPCI) and European Association of Acute Cardiac Care (ACCA) endorsed by the Heart Rhythm Society (HRS), Asia-Pacific Heart Rhythm Society (APHRS), Latin America Heart Rhythm Society (LAHRS), and Cardiac Arrhythmia Society of Southern Africa (CASSA). Eur Heart J 2018, 39(31):2847-2850.

26. Hindricks G, Potpara T, Dagres N, Arbelo E, Bax JJ, Blomstrom-Lundqvist C, Boriani G, Castella M, Dan GA, Dilaveris PE et al: 2020 ESC Guidelines for the diagnosis and management of atrial fibrillation developed in collaboration with the European Association of Cardio-Thoracic Surgery (EACTS). Eur Heart J 2020.

27. Kim YD, Cha MJ, Kim J, Lee DH, Lee HS, Nam CM, Nam HS, Heo JH: Increases in cerebral atherosclerosis according to CHADS2 scores in patients with stroke with nonvalvular atrial fibrillation. Stroke 2011, 42(4):930-934.

28. Neumann FJ, Sousa-Uva M, Ahlsson A, Alfonso F, Banning AP, Benedetto U, Byrne RA, Collet JP, Falk V, Head SJ et al: 2018 ESC/EACTS Guidelines on myocardial revascularization. Eur Heart J 2019, 40(2):87-165.

29. Matsumura-Nakano Y, Shizuta S, Komasa A, Morimoto T, Masuda H, Shiomi H, Goto K, Nakai K, Ogawa H, Kobori A et al: Open-Label Randomized Trial Comparing Oral Anticoagulation With and Without Single Antiplatelet Therapy in Patients With Atrial Fibrillation and Stable Coronary Artery Disease Beyond 1 Year After Coronary Stent Implantation. Circulation 2019, 139(5):604-616.

30. Yasuda S, Kaikita K, Akao M, Ako J, Matoba T, Nakamura M, Miyauchi K, Hagiwara N, Kimura K, Hirayama A et al: Antithrombotic Therapy for Atrial Fibrillation with Stable Coronary Disease. N Engl J Med 2019, 381(12):1103-1113.

31. Lemesle G: Aspirin on Top of Anticoagulation in Patients With Concomitant Stable Coronary Artery Disease and Atrial Fibrillation. Circulation 2019, 139(5):617-619. 
32. Becker RC: Antithrombotic Therapy in Atrial Fibrillation and Coronary Artery Disease. N Engl J Med 2019, 381(12):1169-1170.

\section{Tables}

Table 1 Comparison of baseline characteristics 


\begin{tabular}{|c|c|c|c|c|c|c|}
\hline & \multicolumn{3}{|l|}{ Before PSM } & \multicolumn{3}{|l|}{ After PSM } \\
\hline & $\begin{array}{l}\text { Without } \\
\text { stroke } \\
(n=1997)\end{array}$ & $\begin{array}{l}\text { With stroke } \\
(\mathrm{n}=338)\end{array}$ & $\begin{array}{l}\mathrm{P} \\
\text { value }\end{array}$ & $\begin{array}{l}\text { Without } \\
\text { stroke } \\
(n=1348)\end{array}$ & $\begin{array}{l}\text { With stroke } \\
(n=337)\end{array}$ & $\begin{array}{l}\mathrm{P} \\
\text { value }\end{array}$ \\
\hline Sex & & & 0.771 & & & 0.980 \\
\hline Female & $828(41.46 \%)$ & $\begin{array}{l}143 \\
(42.31 \%)\end{array}$ & & $\begin{array}{l}573 \\
(42.51 \%)\end{array}$ & $\begin{array}{l}143 \\
(42.43 \%)\end{array}$ & \\
\hline Male & $\begin{array}{l}1169 \\
(58.54 \%)\end{array}$ & $\begin{array}{l}195 \\
(57.69 \%)\end{array}$ & & $\begin{array}{l}775 \\
(57.49 \%)\end{array}$ & $\begin{array}{l}194 \\
(57.57 \%)\end{array}$ & \\
\hline Age (years) & $\begin{array}{l}63.00(55.00- \\
69.00)\end{array}$ & $\begin{array}{l}65.00(60.00- \\
72.00)\end{array}$ & $<0.001$ & $\begin{array}{l}64.00 \\
(58.00- \\
70.00)\end{array}$ & $\begin{array}{l}65.00 \\
(60.00- \\
72.00)\end{array}$ & $<0.001$ \\
\hline $\mathrm{BMI}\left(\mathrm{kg} / \mathrm{m}^{2}\right)$ & $\begin{array}{l}25.39(23.44- \\
27.68)\end{array}$ & $\begin{array}{l}25.50(23.23- \\
27.68)\end{array}$ & 0.929 & $\begin{array}{l}25.39 \\
(23.29- \\
27.68)\end{array}$ & $\begin{array}{l}25.50 \\
(23.23- \\
27.68)\end{array}$ & 0.941 \\
\hline \multicolumn{7}{|l|}{ CAD type } \\
\hline SCAD & $128(6.41 \%)$ & $36(10.65 \%)$ & 0.005 & $86(6.38 \%)$ & 36 (10.68\%) & 0.006 \\
\hline UA & $\begin{array}{l}1471 \\
(73.66 \%)\end{array}$ & $229(67.75 \%)$ & 0.024 & $\begin{array}{l}989 \\
(73.37 \%)\end{array}$ & $\begin{array}{l}229 \\
(67.95 \%)\end{array}$ & 0.047 \\
\hline NSTEMI & $286(14.32 \%)$ & $41(12.13 \%)$ & 0.283 & $\begin{array}{l}201 \\
(14.91 \%)\end{array}$ & 41 (12.17\%) & 0.199 \\
\hline STEMI & 79 (3.96\%) & $23(6.80 \%)$ & 0.018 & $51(3.78 \%)$ & $22(6.53 \%)$ & 0.027 \\
\hline Previous MI & 205 (10.27\%) & $49(14.50 \%)$ & 0.021 & $\begin{array}{l}146 \\
(10.83 \%)\end{array}$ & 49 (14.54\%) & 0.057 \\
\hline $\begin{array}{l}\text { Ischaemic } \\
\text { cardiomyopathy }\end{array}$ & $34(1.70 \%)$ & $11(3.25 \%)$ & 0.082 & $23(1.71 \%)$ & $11(3.26 \%)$ & 0.069 \\
\hline Heart failure & $312(15.62 \%)$ & $72(21.30 \%)$ & 0.009 & $\begin{array}{l}228 \\
(16.91 \%)\end{array}$ & 72 (21.36\%) & 0.056 \\
\hline Hypertension & $\begin{array}{l}1307 \\
(65.45 \%)\end{array}$ & $262(77.51 \%)$ & $<0.001$ & $\begin{array}{l}899 \\
(66.69 \%)\end{array}$ & $\begin{array}{l}262 \\
(77.74 \%)\end{array}$ & $<0.001$ \\
\hline Dyslipidaemia & 605 (30.30\%) & $95(28.11 \%)$ & 0.417 & $\begin{array}{l}414 \\
(30.71 \%)\end{array}$ & 94 (27.89\%) & 0.313 \\
\hline $\begin{array}{l}\text { Total } \\
\text { cholesterol } \\
(\mathrm{mmol} / \mathrm{L})\end{array}$ & $\begin{array}{l}3.99(3.40- \\
4.67)\end{array}$ & $\begin{array}{l}3.94(3.32- \\
4.76)\end{array}$ & 0.544 & $\begin{array}{l}4.00(3.37- \\
4.68)\end{array}$ & $\begin{array}{l}3.94(3.32- \\
4.76)\end{array}$ & 0.478 \\
\hline $\begin{array}{l}\text { LDL-C } \\
(\mathrm{mmol} / \mathrm{L})\end{array}$ & $\begin{array}{l}2.51(1.92- \\
3.11)\end{array}$ & $\begin{array}{l}2.45(1.91- \\
3.15)\end{array}$ & 0.615 & $\begin{array}{l}2.51(1.90- \\
3.11)\end{array}$ & $\begin{array}{l}2.45(1.91- \\
3.15)\end{array}$ & 0.567 \\
\hline
\end{tabular}




\begin{tabular}{|c|c|c|c|c|c|c|}
\hline $\begin{array}{l}\text { Valvular heart } \\
\text { disease }\end{array}$ & $43(2.15 \%)$ & $8(2.37 \%)$ & 0.840 & $32(2.37 \%)$ & $8(2.37 \%)$ & 1 \\
\hline $\mathrm{AF}$ & $176(8.81 \%)$ & $48(14.20 \%)$ & 0.002 & 119 (8.83\%) & 48 (14.24\%) & 0.003 \\
\hline AF type & & & $<0.001$ & & & 0.003 \\
\hline No & $\begin{array}{l}1821 \\
(91.19 \%)\end{array}$ & $290(85.80 \%)$ & & $\begin{array}{l}1229 \\
(91.17 \%)\end{array}$ & $\begin{array}{l}289 \\
(85.76 \%)\end{array}$ & \\
\hline Paroxysmal AF & $106(5.31 \%)$ & $22(6.51 \%)$ & & 69 (5.12\%) & $22(6.53 \%)$ & \\
\hline $\begin{array}{l}\text { Nonparoxysmal } \\
\text { AF }\end{array}$ & 70 (3.51\%) & $26(7.69 \%)$ & & $50(3.71 \%)$ & $26(7.72 \%)$ & \\
\hline DM & $551(27.59 \%)$ & $102(30.18 \%)$ & 0.327 & $\begin{array}{l}378 \\
(28.04 \%)\end{array}$ & $\begin{array}{l}102 \\
(30.27 \%)\end{array}$ & 0.418 \\
\hline COPD & $40(2.00 \%)$ & $7(2.07 \%)$ & 0.836 & $30(2.23 \%)$ & $7(2.08 \%)$ & 0.868 \\
\hline CKD & 39 (1.95\%) & $13(3.85 \%)$ & 0.043 & $23(1.71 \%)$ & $13(3.86 \%)$ & 0.015 \\
\hline $\begin{array}{l}\text { Creatine } \\
(\mu \mathrm{mol} / \mathrm{L})\end{array}$ & $\begin{array}{l}69.00(59.00- \\
80.95)\end{array}$ & $\begin{array}{l}72.00(61.30- \\
86.00)\end{array}$ & 0.001 & $\begin{array}{l}70.00 \\
(59.00- \\
82.00)\end{array}$ & $\begin{array}{l}72.00 \\
(61.30- \\
86.00)\end{array}$ & 0.011 \\
\hline Fatty liver & 39 (1.95\%) & $5(1.48 \%)$ & 0.670 & 30 (2.23\%) & $5(1.48 \%)$ & 0.393 \\
\hline Smoker & 409 (20.48\%) & $57(16.86 \%)$ & 0.124 & $\begin{array}{l}261 \\
(19.36 \%)\end{array}$ & 56 (16.62\%) & 0.249 \\
\hline Drinker & 347 (17.38\%) & 47 (13.91\%) & 0.115 & $\begin{array}{l}224 \\
(16.62 \%)\end{array}$ & 46 (13.65\%) & 0.184 \\
\hline $\begin{array}{l}\text { Aortic } \\
\text { atherosclerosis }\end{array}$ & $529(26.81 \%)$ & $146(43.84 \%)$ & $<0.001$ & $\begin{array}{l}386 \\
(28.94 \%)\end{array}$ & $\begin{array}{l}146 \\
(43.98 \%)\end{array}$ & $<0.001$ \\
\hline $\mathrm{LA}(\mathrm{mm})$ & $\begin{array}{l}34.00(32.00- \\
37.00)\end{array}$ & $\begin{array}{l}35.00(32.00- \\
37.00)\end{array}$ & 0.073 & $\begin{array}{l}34.00 \\
(32.00- \\
37.00)\end{array}$ & $\begin{array}{l}35.00 \\
(32.00- \\
37.00)\end{array}$ & 0.024 \\
\hline EF (\%) & $\begin{array}{l}61.74(60.61- \\
62.89)\end{array}$ & $\begin{array}{l}61.70(60.64- \\
62.77)\end{array}$ & 0.574 & $\begin{array}{l}61.74 \\
(60.61- \\
62.86)\end{array}$ & $\begin{array}{l}61.70 \\
(60.64- \\
62.77)\end{array}$ & 0.73 \\
\hline $\mathrm{PWV}(\mathrm{cm} / \mathrm{s})$ & $\begin{array}{l}1556.50 \\
(1367.50- \\
1798.50)\end{array}$ & $\begin{array}{l}1623.00 \\
(1418.00- \\
1906.50)\end{array}$ & $<0.001$ & $\begin{array}{l}1575.25 \\
(1388.00- \\
1814.38)\end{array}$ & $\begin{array}{l}1625.00 \\
(1418.00- \\
1908.62)\end{array}$ & 0.022 \\
\hline $\mathrm{ABI}$ & $\begin{array}{l}1.09(1.02- \\
1.156)\end{array}$ & $\begin{array}{l}1.08(0.97- \\
1.16)\end{array}$ & 0.057 & $\begin{array}{l}1.08(1.01- \\
1.16)\end{array}$ & $\begin{array}{l}1.08(0.97- \\
1.16)\end{array}$ & 0.005 \\
\hline $\mathrm{CHADS}_{2}$ score & $\begin{array}{l}1.00(1.00- \\
2.00)\end{array}$ & $\begin{array}{l}3.00(3.00- \\
4.00)\end{array}$ & $<0.001$ & $\begin{array}{l}1.00(1.00- \\
2.00)\end{array}$ & $\begin{array}{l}3.00(3.00- \\
4.00)\end{array}$ & $\bowtie 0.001$ \\
\hline
\end{tabular}

Abbreviations: $B M /$ body mass index, $C A D$ coronary artery disease, $S C A D$ stable coronary artery disease, UA unstable angina, NSTEMI non-ST-elevation myocardial infarction, STEMIST-elevation myocardial 
infarction, previous $M /$ previous myocardial infarction, $A F$ atrial fibrillation, $D M$ diabetes mellitus, $C O P D$ chronic obstructive pulmonary disease, $C K D$ chronic kidney disease, $L D L-C$ low-density lipoprotein cholesterol, $L A$ left atrial diameter, $E F$ ejection fraction, $P W V$ pulse wave velocity, $A B /$ ankle-brachial index

Table 2 Comparison of baseline characteristics after PSM with or without AF 


\begin{tabular}{|c|c|c|c|}
\hline & Non-AF group $(n=1518)$ & AF group $(n=167)$ & $P$ value \\
\hline Sex & & & 0.505 \\
\hline Female & $641(42.23 \%)$ & $75(44.91 \%)$ & \\
\hline Male & 877 (57.77\%) & $92(55.09 \%)$ & \\
\hline Age (years) & $63.50(58.00-70.00)$ & $69.00(63.00-77.00)$ & $<0.001$ \\
\hline $\mathrm{BMI}\left(\mathrm{kg} / \mathrm{m}^{2}\right)$ & $25.39(23.23-27.68)$ & $25.69(23.44-27.68)$ & 0.872 \\
\hline \multicolumn{4}{|l|}{ CAD type } \\
\hline SCAD & $70(4.61 \%)$ & $52(31.14 \%)$ & $<0.001$ \\
\hline UA & $1132(74.57 \%)$ & $86(51.50 \%)$ & $<0.001$ \\
\hline NSTEMI & $225(14.82 \%)$ & $17(10.18 \%)$ & 0.104 \\
\hline STEMI & $71(4.68 \%)$ & $2(1.20 \%)$ & 0.036 \\
\hline Previous MI & $166(10.94 \%)$ & $29(17.37 \%)$ & 0.014 \\
\hline Ischaemic cardiomyopathy & $24(1.58 \%)$ & $10(5.99 \%)$ & $<0.001$ \\
\hline Heart failure & $211(13.90 \%)$ & $89(53.29 \%)$ & $<0.001$ \\
\hline Hypertension & $1041(68.58 \%)$ & $120(71.86 \%)$ & 0.385 \\
\hline Dyslipidaemia & $456(30.04 \%)$ & $52(31.14 \%)$ & 0.769 \\
\hline Total cholesterol (mmol/L) & $4.00(3.39-4.70)$ & $3.83(3.28-4.70)$ & 0.229 \\
\hline LDL-C (mmol/L) & $2.52(1.91-3.12)$ & $2.32(1.88-3.09)$ & 0.301 \\
\hline Valvular heart disease & $29(1.91 \%)$ & $11(6.59 \%)$ & $<0.001$ \\
\hline DM & $430(28.33 \%)$ & $50(29.94 \%)$ & 0.661 \\
\hline COPD & $35(2.31 \%)$ & $2(1.20 \%)$ & 0.354 \\
\hline CKD & $28(1.84 \%)$ & $8(4.79 \%)$ & 0.012 \\
\hline Creatine $(\mu \mathrm{mol} / \mathrm{L})$ & $69.00(59.00-81.00)$ & 79.85 (68.00-94.75) & $<0.001$ \\
\hline Fatty liver & $33(2.17 \%)$ & $2(1.20 \%)$ & 0.401 \\
\hline Smoker & $296(19.50 \%)$ & $21(12.57 \%)$ & 0.03 \\
\hline Drinker & $249(16.40 \%)$ & $21(12.57 \%)$ & 0.201 \\
\hline Aortic atherosclerosis & $458(30.53 \%)$ & $74(44.58 \%)$ & $<0.001$ \\
\hline
\end{tabular}




\begin{tabular}{|llll|}
\hline $\mathrm{LA}(\mathrm{mm})$ & $34.00(32.00-36.00)$ & $38.00(35.00-42.50)$ & $<0.001$ \\
\hline $\mathrm{EF}(\%)$ & $61.74(60.64-62.89)$ & $60.78(55.48-62.05)$ & 0.001 \\
\hline $\mathrm{ABI}$ & $1565.00(1387.75-1810.75)$ & $1734.75(1505.88-2149.62)$ & $<0.001$ \\
\hline CHADS ${ }_{2}$ score & $1.08(1.00-1.16)$ & $1.06(0.94-1.14)$ & 0.004 \\
\hline Stroke & $1.00(1.00-2.00)$ & $2.00(1.00-3.00)$ & $<0.001$ \\
\hline
\end{tabular}

Abbreviations: $B M /$ body mass index, $C A D$ coronary artery disease, SCAD stable coronary artery disease, UA unstable angina, NSTEMInon-ST-elevation myocardial infarction, STEMIST-elevation myocardial infarction, previous $M /$ previous myocardial infarction, $A F$ atrial fibrillation, $D M$ diabetes mellitus, $C O P D$ chronic obstructive pulmonary diseases, $C K D$ chronic kidney disease, $L D L-C$ low-density lipoprotein cholesterol, $L A$ left atrial diameter, $E F$ ejection fraction, $P W V$ pulse wave velocity, $A B /$ ankle-brachial index

Table 3 Univariate and multivariate analysis of the association between AF and ischaemic stroke after PSM

\begin{tabular}{|c|c|c|c|}
\hline & Univariate & Model I & Model II \\
\hline \multirow[t]{2}{*}{$\mathrm{AF}$} & OR $(95 \% \mathrm{Cl})$ & OR $(95 \% \mathrm{Cl})$ & OR $(95 \% \mathrm{Cl})$ \\
\hline & $P$ value & $P$ value & $P$ value \\
\hline No & 1.0 & 1.0 & 1.0 \\
\hline Paroxysmal & $1.36(0.83-2.23) 0.2296$ & $0.97(0.49-1.94) 0.9309$ & $0.97(0.48-1.94) 0.9271$ \\
\hline Nonparoxysmal & $2.21(1.35-3.61) 0.0015$ & $1.06(0.47-2.40) 0.8876$ & $1.01(0.44-2.32) 0.9776$ \\
\hline
\end{tabular}

Model I was adjusted for stable angina, aortic atherosclerosis, left atrial diameter, pulse wave velocity, and $\mathrm{CHADS}_{2}$ score.

Model II was adjusted for STEMI, previous myocardial infarction, ischaemic cardiomyopathy, CKD, and factors in model I.

\section{Figures}




\section{Hospitalized}

patients between

Sep.2016 and

May.2019

$(\mathrm{n}=5583)$

Patients with

$\mathrm{CAD}(\mathrm{n}=2597)$

\section{Patients included}

262 Patients excluded for cerebral hemorrhage, subarachnoid hemorrhage, unknown of stroke history

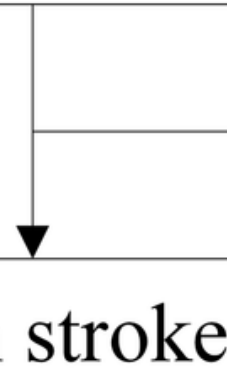

$(n=338)$

Without stroke $(\mathrm{n}=1997)$

Figure 1

Patient selection flowchart. 


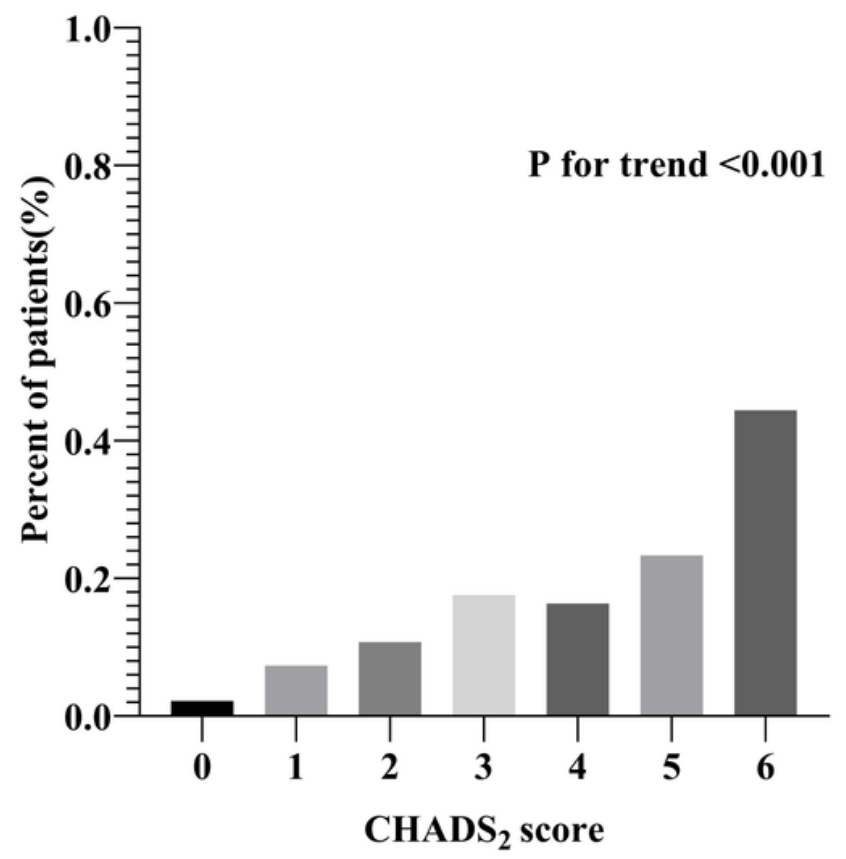

(a)

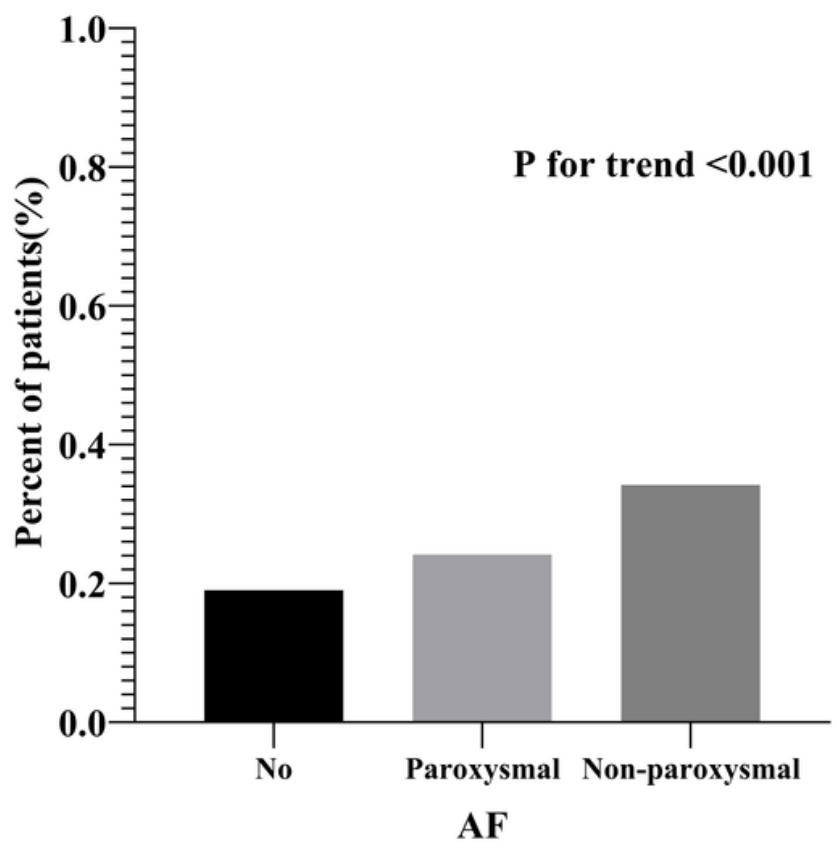

(b)

Figure 2

(a) Association between CHADS2 score and AF. (b) Association between AF type and ischaemic stroke. 


\begin{tabular}{|c|c|c|c|c|c|c|c|c|}
\hline Subgroup & No. of patients & AF group & Non-AF group & & & Odds Ratio $(95 \% \mathrm{Cl})$ & $P$ value & $P$ Value for interaction \\
\hline Overall & 1685 & $48(28.74 \%)$ & $289(19.04 \%)$ & & $\longrightarrow$ & $1.72(1.20-2.46)$ & 0.0032 & \\
\hline Sex & & & & & & & & 0.097 \\
\hline Female & 716 & $17(22.67 \%)$ & $126(19.66 \%)$ & $\longmapsto$ & $\rightarrow$ & $1.20(0.67-2.13)$ & 0.5377 & \\
\hline Male & 969 & $31(33.70 \%)$ & $163(18.59 \%)$ & & $\mapsto$ & $2.23(1.40-3.54)$ & 0.0007 & \\
\hline Age & & & & & & & & 0.9604 \\
\hline$<65$ & 873 & $14(25.00 \%)$ & $138(16.89 \%)$ & & $\longrightarrow$ & $1.64(0.87-3.09)$ & 0.1249 & \\
\hline$>=65$ & 812 & $34(30.63 \%)$ & $151(21.54 \%)$ & & $\mapsto$ & $1.61(1.03-2.50)$ & 0.0351 & \\
\hline BMI & & & & & & & & 0.2777 \\
\hline$<24$ & 540 & $12(23.08 \%$ & $94(19.26 \%)$ & $\vdash$ & $\rightarrow \longrightarrow$ & $1.26(0.63-2.49)$ & 0.5111 & \\
\hline$>=24$ & 1145 & $36(31.30 \%)$ & $195(18.93 \%)$ & & $\mapsto$ & $1.95(1.28-2.98)$ & 0.002 & \\
\hline SCAD & & & & & & & & 0.3613 \\
\hline No & 1563 & $28(24.35 \%)$ & $273(18.85 \%)$ & & -1 & $1.39(0.89-2.16)$ & 0.1519 & \\
\hline Yes & 122 & $20(38.46 \%)$ & $16(22.86 \%)$ & & $\longrightarrow$ & $2.11(0.96-4.65)$ & 0.0639 & \\
\hline UA & & & & & & & & 0.271 \\
\hline No & 467 & $28(34.57 \%)$ & $80(20.73 \%)$ & & •— & $2.02(1.20-3.40)$ & 0.008 & \\
\hline Yes & 1218 & $20(23.26 \%)$ & $209(18.46 \%)$ & & $\longrightarrow$ & $1.34(0.79-2.26)$ & 0.2742 & \\
\hline NSTEMI & & & & & & & & 0.8827 \\
\hline No & 1443 & $44(29.33 \%)$ & $252(19.49 \%)$ & & $\mapsto$ & $1.71(1.18-2.50)$ & 0.0051 & \\
\hline Yes & 242 & $4(23.53 \%)$ & $37(16.44 \%)$ & & 一- & $1.56(0.48-5.06)$ & 0.4559 & \\
\hline STEMI & & & & & & & & 0.1289 \\
\hline No & 1612 & $48(29.09 \%)$ & $267(18.45 \%)$ & & $\mapsto-1$ & $1.81(1.26-2.60)$ & 0.0012 & \\
\hline Yes & 73 & $0(0.00 \%)$ & $22(30.99 \%)$ & & & $0.00(0-12.45)$ & 1 & \\
\hline Previous MI & & & & & & & & 0.6662 \\
\hline No & 1490 & $39(28.26 \%)$ & $249(18.42 \%)$ & & $\mapsto$ & $1.75(1.18-2.59)$ & 0.0058 & \\
\hline Yes & 195 & $9(31.03 \%)$ & $40(24.10 \%)$ & $\vdash$ & - & $1.42(0.60-3.36)$ & 0.4283 & \\
\hline Ischmic cardiomyopathy & & & & & & & & 0.4433 \\
\hline No & 1651 & $43(27.39 \%)$ & $283(18.94 \%)$ & & $\mapsto$ & $1.61(1.11-2.35)$ & 0.0121 & \\
\hline Yes & 34 & $5(50.00 \%)$ & $6(25.00 \%)$ & & $\longrightarrow$ & $3.00(0.64-14.08)$ & 0.1637 & \\
\hline CHADS2 score $>=3$ & & & & & & & & 0.3759 \\
\hline No & 1280 & $3(3.23 \%)$ & $40(3.37 \%)$ & & $\longrightarrow$ & $0.96(0.29-3.15)$ & 0.9408 & \\
\hline \multirow[t]{2}{*}{ Yes } & 405 & 45 (60.81\%) & 249 (75.23\%) & $\longmapsto$ & & $0.51(0.30-0.87)$ & 0.0129 & \\
\hline & & & 0.1 & 1. & $\begin{array}{lcc} & 1 & \\
0 & 2.0 & 5.0\end{array}$ & & & \\
\hline
\end{tabular}

\section{Figure 3}

Association between AF and ischaemic stroke in prespecified and exploratory subgroups after PSM. P for interaction is based on the likelihood ratio test. Abbreviations: BMI body mass index, SCAD stable coronary artery disease, UA unstable angina, NSTEMI non-ST-elevation myocardial infarction, STEMI STelevation myocardial infarction, previous MI previous myocardial infarction 